\title{
ORIGINAL ARTICLE \\ Burden and quality of life among caregivers of children and adolescents with meningomyelocele: measuring the relationship to anxiety and depression
}

\author{
MP Valença ${ }^{1}$, TA de Menezes ${ }^{2}$, AA Calado $^{3}$ and G de Aguiar Cavalcanti ${ }^{3}$
}

Objectives: This study aimed to assess the burden and quality of life (Qol) of primary caregivers of children/adolescents with meningomyelocele, taking into account the relationship to anxiety and depression symptoms.

Methods: A cross-sectional approach was taken to analyze the health-related Qol and burden using the Short Form-36 Survey (SF-36) and the Caregiver Burden Scale (CBS), respectively. Depressive and anxiety symptoms were investigated using the Beck Inventories. The Heckman two-step method was used to deal with the selection bias problem.

Results: A total of 43 primary caregivers were enrolled in the study. Most of the caregivers were mothers with preliminary education, living in consensual union. Lower scores in general health and vitality were reported in the SF-36. The mean global CBS score was 2.2. Majority of the volunteers (55.8\%) were considered non-depressive. There were both positive and negative correlations between the scores of both Beck Inventories and most dimensions of the CBS and SF-36. The Heckman method showed a higher burden among caregivers who had children with fecal incontinence, were living together with a partner, were unemployed and had lower income $(P<0.05)$.

Conclusion: The primary caregivers of children and adolescents with myelomeningocele reported burden and a lower Qol. There were more anxiety and depression symptoms in subjects with higher burden and impaired Qol. Caregivers had a higher burden if they were living together with a partner, were unemployed, had low income and had care recipients with fecal incontinence.

Spinal Cord (2012) 50, 553-557; doi:10.1038/sc.2012.10; published online 6 March 2012

Keywords: caregivers; quality of life; meningomyelocele; depression; anxiety; personal satisfaction

\section{INTRODUCTION}

Myelomeningocele (MMC) is a defect of the neural tube, with neurological injury due to protrusion of the spinal nerve tissue covered by skin, causing bladder and bowel dysfunctions, anatomical abnormalities, and locomotor and sensory impairment below the level of injury. These changes are closely related to individual and social aspects that are chronic, and may have significant meaning in terms of clinical, therapeutic, emotional and social aspects. ${ }^{1}$ The complex condition in children with MMC may result in integration difficulties in school and social life, because these children are very dependent on their caregivers. Moreover, they need constant care and supervision, leading to physical and emotional consequences for both the individual and the caregiver. Caregiving affects physical health by exposing the individual to constant stress, making the caregiver tired and sometimes preventing behaviors of self-care.

The quality of life (Qol) of caregivers of patients with chronic conditions has been discussed in studies involving the elderly and children with malignancies. However, the assessment of Qol and burden for primary caregivers of patients with MMC is still limited. Burden may depend on the time devoted to the patient as well as on the support network that the caregiver has. It may also depend on the cause-and-effect relationship between them, such that the higher the financial position, the worse the Qol. ${ }^{2}$
On the assumption that the primary caregivers of patients with MMC experience many problems related to daily living, which result in impaired Qol and increased overhead, this study aimed to investigate the burden and Qol, as well as anxiety and depressive symptoms, among the caregivers of children with MMC.

\section{MATERIALS AND METHODS}

A cross-sectional descriptive approach with a convenience sampling technique was used. Three trained researchers collected data from the children and caregivers in face-to-face interviews after a nursing consultation. Written informed consent was obtained. All applicable institutional regulations concerning the ethical use of human volunteers were followed during the course of this research. The questionnaires were administered through interview for standardization of the collected data. All the participants completed the study questionnaire and showed no difficulty in understanding the instruments.

During 2009, we enrolled 43 caregivers of children with meningomyelocele and neurogenic bladder, who were treated at the Division of Urology of the University of Pernambuco (Recife, Brazil). The primary caregivers of children/ adolescents aged $0-15$ years and who provided daily care for the past 6 months were included. Caregivers had to have sufficient language skills to participate in the interviews. Qol was measured by the Portuguese version of the Medical Outcomes Study Short Form-36 Survey (SF-36). ${ }^{3}$ This generic instrument consists of 36 items of the following eight domains: physical functioning, role limitations due to physical health problems, bodily pain, general health

\footnotetext{
${ }^{1}$ Universidade de Pernambuco (UPE) / Faculdade Pernambucana de Saúde (FPS), Recife, Pernambuco, Brazil; ${ }^{2} \mathrm{CNPq}$ Researcher, Therapeutic Innovations Post-Graduation Program (PPGIT) and PIMES, Universidade Federal de Pernambuco - UFPE, Recife, Pernambuco, Brazil and ${ }^{3}$ Division of Urology Universidade de Pernambuco (UPE), Recife, Pernambuco, Brazil

Correspondence: Dr G de Aguiar Cavalcanti, Division of Urology, Universidade de Pernambuco (UPE), Rua de Apipucos 235/2202, Recife - Pernambuco - Brazil. E-mail: geraldo.cavalcanti@sbu.org.br
}

Received 8 August 2011; revised 12 December 2011; accepted 29 December 2011; published online 6 March 2012 
perceptions, vitality, social functioning, role limitations due to emotional problems and mental health. The scores for each domain range from 0 to 100 , with higher scores representing better health.

The Caregiver Burden Scale (CBS) is a questionnaire that was originally proposed by Oremark in Swedish and was adapted by Medeiros et al. ${ }^{4}$ to measure the subjective impact on caregivers of patients with chronic diseases. It is a specific instrument that assesses the general aspects of Qol in this population. It consists of 22 questions divided into five dimensions: general strain, isolation, disappointment, emotional involvement and environment. Higher scores mean a higher burden.

The Beck Depression Inventory (BDI) was used to measure the behavioral manifestations of depression. The inventory survey consists of 21 categories of symptoms and activities, with four alternatives each, in ascending order of level of depression. The total of the scores identifies the level of depression, suggesting the following output: 0 to 10 , non-depressive; $>10$, depressive. The Beck Anxiety Inventory (BAI) was also proposed by Beck to measure the common symptoms of anxiety. The inventory consists of 21 symptoms with four alternatives each, with higher scores representing a higher anxiety level.

The Statistical Package for Social Sciences (SPSS) 13.0 version and Stata 9.0 version were used for data analysis. Student's $t$-test or the Mann-Whitney $U$ test was used to compare the demographic variables. The correlations among numeric variables were assessed using Pearson's $r$ coefficient and Spearman's $r$ coefficient. To identify the impact of the children's malformations on the burden of caregivers, controlling for socioeconomic characteristics, we used ordinary least squares estimation.

The data, however, suggested a correlation between depressive caregivers and higher burden. In this case, ordinary least squares estimation presented a selection bias problem. ${ }^{5}$ To control this problem, the Heckman method was run in two stages. In the first stage, a probit regression was run, the probability of being depressive was identified and the inverse mills ratio was calculated. In the second step, the mills ratio was used as the instrument in ordinary least squares regression to control the bias problem. To estimate the multivariable selection, probit, ordinary least squares and the Heckman model were used. $P$-values $<0.05$ were considered statistically significant.

\section{RESULTS}

Table 1 describes the demographic characteristics of the caregivers. Their ages ranged from 18 to 54 years. Most of the caregivers were mothers, non-white, living in consensual union and had completed preliminary education. Most of them were required to take care of one to three children, and to live with the care recipients and with other children. Most of the caregivers were unemployed, informal caregivers and living in their own house (Table 2).

The majority of patients with MMC had severe motor impairment, sensitivity impairment and anal incompetence, and also presented detrusor overactivity. They also had physical malformations, such as clubfoot and hydrocephalus (Table 3 ).

Table 4 presents the dimensions of the SF- 36 and the CBS, as well as the BAI and BDI results. The dimensions of the SF- 36 that received the lowest scores were general health and vitality. The mean global score of the CBS was $2.2 \pm 0.6$. The scores ranged from $1.3 \pm 0.47$ for emotional involvement to $2.59 \pm 0.79$ for environment. According to the BDI, $44.2 \%$ of the patients were considered depressive (BDI $\geqslant 10$ ). The BAI inventory scores were $0-9$ in $30(69.7 \%), 10-16$ in $6(13.9 \%), 17-29$ in $5(11.6 \%)$, and $>30$ in $2(4.6 \%)$ subjects.

There was a correlation between SF-36 and CBS dimensions and $\mathrm{BDI}$ and BAI scores. The BAI showed a significant negative correlation with the physical function, bodily pain, social function and mental health dimensions of the SF-36 $(P<0.05)$. There was a significant positive correlation between the BAI and the general strain, isolation, disappointment and environment dimensions, and the global score of the CBS $(P<0.05)$.

The BDI showed a significant negative correlation with the bodily pain, general health, vitality, social function and mental health
Table 1 Socio-demographic data of primary caregivers of children and adolescents with meningomyelocele

\begin{tabular}{|c|c|c|}
\hline Variables & $\mathrm{N}$ & $\%$ \\
\hline \multicolumn{3}{|l|}{ Gender } \\
\hline Male & 2 & 4.7 \\
\hline Female & 41 & 95.3 \\
\hline \multicolumn{3}{|l|}{ Race } \\
\hline Non-white & 30 & 69.7 \\
\hline White & 10 & 23.3 \\
\hline Black & 3 & 7.0 \\
\hline \multicolumn{3}{|l|}{ Family relationship } \\
\hline Mother & 38 & 88.3 \\
\hline Father & 2 & 4.7 \\
\hline Grandmother & 2 & 4.7 \\
\hline Aunt & 1 & 2.3 \\
\hline \multicolumn{3}{|l|}{ Marital status } \\
\hline Consensual union & 15 & 34.9 \\
\hline Married & 8 & 18.6 \\
\hline Divorced & 7 & 16.3 \\
\hline Single & 13 & 30.2 \\
\hline \multicolumn{3}{|l|}{ Educational level } \\
\hline Illiterate & 1 & 2.3 \\
\hline Incomplete preliminary education & 12 & 27.9 \\
\hline Complete preliminary education & 16 & 37.2 \\
\hline Incomplete high school & 4 & 9.3 \\
\hline Complete high school & 10 & 23.3 \\
\hline Mean age (mean \pm s.d. in years) & $35 \pm 8.8$ & \\
\hline
\end{tabular}

domains of the SF-36 $(P<0.05)$. The BDI correlated positively with all the dimensions of the CBS $(P<0.05)$, except emotional involvement. Depression correlated with the general health, social aspects and mental health dimensions of the SF-36, the general strain and total scores of the CBS, and with BAI scores.

The general health, social aspects and mental health domains of the SF-36 were correlated with depression. No significant difference was found in the mean scores of any other caregivers' social demographics or the children's clinical characteristics $(P>0.05)$.

With Heckman estimation, the presence of fecal incontinence in the care recipients, low household income, unemployed status and living together with partners presented significant coefficients. Burden among caregivers increases when the children in their care have fecal incontinence and when the caregivers are married. Higher income and having a job decrease the burden. For this estimation, however, child dysfunctions and characteristics such as motor and sensitivity impairment, associated malformations, bladder function and age, as well as the caregiver being the household head, were not significant to cause burden (Table 5).

\section{DISCUSSION}

Almost the entire sample was made up of females. All the caregivers were relatives of the care recipients. Mothers are predominant as the primary caregivers of children with cerebral palsy. ${ }^{6}$ Blanes et al. ${ }^{7}$ found that $81.7 \%$ of caregivers of paraplegic patients were women (including mothers, wives and daughters). About $90 \%$ of the caregivers of persons with chronic diseases are their relatives. ${ }^{8}$ Scarpelli et al. ${ }^{9}$ 
Table 2 Socio-demographic data of primary caregivers of children and adolescents with meningomyelocele

\begin{tabular}{|c|c|c|}
\hline Variables & $\mathrm{N}$ & $\%$ \\
\hline \multicolumn{3}{|l|}{ Caregiver type } \\
\hline Informal & 43 & 100.0 \\
\hline \multicolumn{3}{|l|}{ Occupation } \\
\hline Housewife/unemployed & 32 & 74.4 \\
\hline Caregiver and employed & 11 & 25.6 \\
\hline \multicolumn{3}{|l|}{ Household head } \\
\hline Yes & 9 & 20.9 \\
\hline No & 34 & 79.1 \\
\hline \multicolumn{3}{|l|}{ Daily work hours } \\
\hline Unemployed & 32 & 74.4 \\
\hline Part-time job & 8 & 18.6 \\
\hline Full-time job & 3 & 7.0 \\
\hline \multicolumn{3}{|l|}{ Living with care recipients } \\
\hline No & 8 & 18.6 \\
\hline Yes & 35 & 81.4 \\
\hline \multicolumn{3}{|l|}{ Have other children } \\
\hline None & 14 & 32.6 \\
\hline $1-3$ & 23 & 53.5 \\
\hline $4-6$ & 5 & 11.6 \\
\hline $6-9$ & 1 & 2.3 \\
\hline \multicolumn{3}{|l|}{ Monthly income } \\
\hline $1 \mathrm{MS}^{\mathrm{a}}$ & 10 & 23.3 \\
\hline $2 \mathrm{MS}^{\mathrm{a}}$ & 28 & 65.1 \\
\hline $2-4 \mathrm{MS}^{\mathrm{a}}$ & 5 & 11.6 \\
\hline \multicolumn{3}{|l|}{ Type of residence } \\
\hline Homeowner & 32 & 74.4 \\
\hline Renter & 11 & 25.6 \\
\hline
\end{tabular}

aBrazilian minimal salary: $1 \mathrm{MS}=\mathrm{R} \$ 465.00$ (US\$273.00) in 2009.

studied the pediatric health-related Qol in children with cancer and found mothers to be the primary caregivers in $76.8 \%$ of the cases. Other studies demonstrated that mothers are usually the informants and devote more time to care. ${ }^{10,11}$ We also found a high percentage of mothers acting as caregivers, accepting the role and responsibilities associated with the care of children with special needs. Crowe et al. ${ }^{11}$ noted that this division of labor has been going on since the $1960 \mathrm{~s}$, and no changes were found when women entered the workforce.

Although our study was controlled for several variables, bias might have been introduced with the administration by interview of questionnaires designed to be answered in written form. We decided to do it this way to standardize the collected data because some caregivers could be illiterate or might not have completed preliminary education, which could compromise the accomplishment of self-questionnaires.

Majority of the caregivers live together with their partners. Mugno et al. ${ }^{12}$ found that $74 \%$ of the caregivers of children with pervasive developmental disorders were married or living together. However, this study did not demonstrate the impact that conjugal life can represent in a mother-caregiver. Living together with a partner and having a disabled child may lead to increased stress on the mothercaregiver. Mothers usually feel that they cannot separate child and
Table 3 Clinical characteristics of children and adolescents with meningomyelocele

\begin{tabular}{|c|c|c|}
\hline Variables & N & $\%$ \\
\hline \multicolumn{3}{|l|}{ Motor impairment } \\
\hline Paraplegia & 12 & 27.9 \\
\hline Paraparesis & 17 & 39.5 \\
\hline Uncoordinated motricity & 8 & 18.6 \\
\hline Non-motor impaired & 6 & 14.0 \\
\hline \multicolumn{3}{|l|}{ Sensorial impairment } \\
\hline Absent sensation & 17 & 39.5 \\
\hline Reduced sensation & 24 & 55.8 \\
\hline Preserved sensation & 2 & 4.7 \\
\hline \multicolumn{3}{|l|}{ Anorectal function } \\
\hline Constipated & 18 & 41.9 \\
\hline Anal incompetence & 21 & 48.8 \\
\hline Preserved function & 4 & 9.3 \\
\hline \multicolumn{3}{|l|}{ Bladder function } \\
\hline Detrusor overactivity & 32 & 74.4 \\
\hline Poor compliance+acontractile detrusor & 5 & 11.6 \\
\hline Detrusor underactivity & 6 & 14.0 \\
\hline \multicolumn{3}{|l|}{ Malformations } \\
\hline None & 6 & 14.0 \\
\hline Clubfoot & 19 & 44.2 \\
\hline Hydrocephalus & 4 & 9.3 \\
\hline Hydrocephalus+clubfoot & 13 & 30.2 \\
\hline Imperforate anus+clubfoot & 1 & 2.3 \\
\hline Mean age (mean \pm s.d. in years) & $6.2 \pm 4.3$ & \\
\hline
\end{tabular}

partner care, leading to feelings of guilt. The functioning and wellbeing of parents depend on the child's situation as well. Other authors have emphasized that severe illness can disrupt family life, cause family dysfunction, strain resources and burden the caregiver. The family's ability to cope with crises depends on their resources. ${ }^{13}$

The caregiving occupation has been analyzed in a few studies on the caregivers of elderly people, which have demonstrated that $58 \%$ of caregivers are unemployed or retired. ${ }^{14}$ The majority of caregivers in the present study were housewives or unemployed; however, having a job did represent less burden. Caregivers with jobs spent less time per day dealing with children's disabilities and difficulties in self-care and felt less burdened. Additionally, those who work generally bring home a better income than do unemployed individuals, providing children with material necessities and presenting a lower level of burden. Physical and economic health probably mitigates the stress of caregiving. ${ }^{15}$ The level of Qol in the families of children with severe clinical conditions may be moderated by a complex matrix of environmental and clinically based variables, such as socioeconomic status, social support, and parental and child characteristics.

Qol has become an important topic in health research. The findings of the present study should contribute towards the adjustment of the treatment and help extended to patients and their families. We used a valid and reproducible instrument to measure Qol and a specific questionnaire to assess burden of care. Few studies have examined Qol in caregivers of children or adolescents with chronic diseases. Our results show that the scores in the physical function and social function dimensions are consistent with those in previous studies, 
and a higher impact on scores resulted from physical and emotional dimensions. Rösler-Shidlack et al. ${ }^{16}$ evaluated the Qol of family caregivers in a district in Germany and also found lower scores in all the eight dimensions of the SF-36, especially in daily and social activities.

Table 4 Scores of SF-36 dimensions, CBS dimensions and Beck inventories for caregivers of children and adolescents with meningomyelocele

\begin{tabular}{|c|c|c|c|c|c|}
\hline \multirow[t]{2}{*}{ Dimensions } & \multicolumn{5}{|c|}{ 95\% Confidence interval } \\
\hline & Mean & s.d. & Median & Lower limit & Upper limit \\
\hline \multicolumn{6}{|l|}{$S F-36$} \\
\hline Physical function & 81.9 & 19.6 & 85.0 & 70.0 & 100.0 \\
\hline Role physical & 74.4 & 33.4 & 100.0 & 50.0 & 100.0 \\
\hline Body pain & 62.1 & 31.1 & 61.0 & 41.0 & 100.0 \\
\hline General health & 53.2 & 17.4 & 55.0 & 37.0 & 67.0 \\
\hline Vitality & 55.9 & 25.4 & 60.0 & 35.0 & 70.0 \\
\hline Social function & 76.5 & 22.5 & 75.0 & 62.5 & 100.0 \\
\hline Role emotional & 65.1 & 45.4 & 100.0 & 0.0 & 100.0 \\
\hline Mental health & 58.6 & 19.4 & 60.0 & 48.0 & 72.0 \\
\hline \multicolumn{6}{|l|}{$C B S$} \\
\hline General strain & 2.5 & 0.8 & 2.4 & 1.6 & 3.0 \\
\hline Isolation & 1.8 & 0.8 & 1.7 & 1.0 & 2.3 \\
\hline Disappointment & 2.3 & 0.9 & 2.4 & 1.6 & 3.0 \\
\hline Emotional involvement & 1.3 & 0.5 & 1.0 & 1.0 & 1.7 \\
\hline Environment & 2.6 & 0.8 & 2.3 & 2.0 & 3.3 \\
\hline Global score & 2.2 & 0.6 & 2.4 & 1.6 & 2.6 \\
\hline General sum & 10.5 & 2.6 & 11.2 & 8.1 & 12.2 \\
\hline \multicolumn{6}{|l|}{ Beck inventories } \\
\hline Anxiety (BAI) & 8.8 & 9.9 & 5.0 & 3.0 & 11.0 \\
\hline Depression (BDI) & 10.5 & 8.8 & 9.0 & 5.0 & 14.0 \\
\hline
\end{tabular}

Abbreviations: BAI, Beck Anxiety Inventory; BDI, Beck Depression Inventory; CBS, Caregiver Burden Scale.
A higher burden was observed in the environment and general strain dimensions. Other authors demonstrated a higher impact in the environment and disappointment dimensions of the CBS among caregivers of patients with chronic diseases. ${ }^{17}$ The lower socioeconomic level of subjects in our study might partly explain the higher impact in the environment dimension, which involves some needs of disabled children, such as wheelchairs, bath chairs and special adaptations in the home or in public. Other authors also emphasize that environmental changes have already been achieved in Brazil for people with disabilities, but reduced public transportation access and buildings and sidewalks without wheelchair ramps represent a problem that may affect people with special needs and their caregivers. ${ }^{7}$

Depressive state was frequent. Family caregivers also have a deep interpersonal contact with their relatives for a long time, which might result in emotional exhaustion and burden. Takahashi et al. ${ }^{18}$ demonstrated that informal caregivers were depressed compared with professional caregivers, and that depression correlated with the psychological aspects of Qol and the role strain factors of burden. Depression and anxiety have been poorly analyzed in children's caregivers. Caregiving may also affect other aspects of health, such as one's subjective overall health, use of preventive health care, employment interruptions and social isolation. Takai et al. ${ }^{19}$ investigated burnout, depression and the Qol of caregivers of persons with dementia, and found that higher levels of burnout corresponded to higher levels of depressive symptoms and lower Qol. A comprehensive meta-analysis of the mental and physical health effects of caregiving evidenced significantly higher rates of depression and stress in caregivers compared with noncaregivers. ${ }^{20}$ Continuous and intensive caregiving work environments might lead to poor mental health outcomes and Qol.

Burden had a higher impact on those caregivers who had charge of children with anorectal incontinence, which may be explained by the daily dependence on diapers and the smell of feces. The psychosocial stress may result from the disease parameters, such as illness severity and functional limitations on the child, and may also be due to the continuous dependence on caregivers to do daily activities. The high

Table 5 Impact of children's clinical characteristics on burden (CBS) of non-depressive caregivers of children and adolescents with meningomyelocele

\begin{tabular}{|c|c|c|c|c|}
\hline \multirow[t]{2}{*}{ Variables } & \multicolumn{2}{|c|}{ Ordinary least squares } & \multicolumn{2}{|c|}{ Heckman two-step } \\
\hline & Coefficient & P-value & Coefficient & $\mathrm{P}$-value \\
\hline Motor impairment child & 0.086 & 0.921 & 1.302 & 0.288 \\
\hline Sensitivity impairment child & $-0,418$ & 0.487 & -1.166 & 0.171 \\
\hline Anorectal function child & 0.775 & 0.387 & 2.071 & 0.041 \\
\hline Malformation child & 1.021 & 0.256 & 0.113 & 0.916 \\
\hline Bladder function & -0.311 & 0.800 & -0.517 & 0.735 \\
\hline Household head & 1.851 & 0.113 & 2.025 & 0.231 \\
\hline Children age & 0.213 & 0.032 & 0.104 & 0.410 \\
\hline Daily work hours & -1.780 & 0.063 & -2.693 & 0.028 \\
\hline Monthly income & -0.855 & 0.022 & -1.385 & 0.027 \\
\hline Marital status & 2.341 & 0.003 & 2.546 & 0.011 \\
\hline Constant & 11.763 & 0.000 & 15.179 & 0.000 \\
\hline$R^{2}$ & 0.4081 & & & \\
\hline Inverse Mills ratio ${ }^{a}$ & & & $\lambda=-2.436$ & $\mathrm{Cl}=-5.186$ to 0.3132 \\
\hline Obs & 43 & & 43 & \\
\hline
\end{tabular}

avariable derived from the Heckman Selection Equation. Significant mean $P$-value $<0.05$ are in bold. 
incidence of fecal incontinence suggests that the patients were not on a colonic washout regimen. Addressing this situation would be important to decrease the burden of caregivers, as well as to increase the chances of the children's acceptance into public school, which would be difficult if these children are not able to perform self-care actions, such as changing diapers by themselves.

We hypothesize that informal caregivers should have another occupation as a part-time job to earn higher income and have a better Qol, and that a colonic washout regimen in children must not be overlooked.

\section{CONCLUSION}

The primary caregivers of children and adolescents with MMC reported a lower Qol and a higher burden. There were more anxiety and depression symptoms in subjects with burden and impaired Qol. Caregivers experienced a higher burden if they were living together with a partner, were unemployed, had low income and had care recipients with fecal incontinence.

\section{DATA ARCHIVING}

There were no data to deposit.

\section{CONFLICT OF INTEREST}

The authors declare no conflict of interest.

\section{ACKNOWLEDGEMENTS}

We thank all the individuals who performed interviews and provided the information to make this report possible. We also thank the nursing students, Paula Almeida and Vanessa Andrade, for their collaboration in data collection.

1 Furlan MFFM, Ferriani MGC, Gomes R. Caring for children with neurogenic bladder dysfunction: social representation of these children's and their mothers' needs. Latin Am J Nurs 2003; 11: 763-770.

2 Amendola F, Oliveira MAC, Alvarenga MRM. Quality of life of family caregivers for disabled dependent patients receiving home care as part of the Municipal Family Health Program. Text Context - Nurs 2008; 17: 266-272.
3 Ciconelli RM, Ferraz MB, Santos WS, Meinão I, Quaresma MR. Brazilian- Portuguese version of the SF-36: a reliable and valid quality of life outcome measure. Braz $J$ Rheumatol 1999; 39: 143-150.

4 Medeiros MMC, Ferraz MB, Quaresma MR, Rodrigues M, Menezes AP. Adaptation and validation of the caregiver burden scale to Brazilian cultural milieu. Braz J Rheumatol 1998; 38: 193-199.

5 Heckman JJ. Sample selection bias as a specification error. Econometrica 1979; 47 . $153-161$.

6 Camargos ACR, Lacerda TTB, Viana SO, Pinto LRA, Fonseca MLS. Assessment of the caregiver burden of children with cerebral palsy using the Burden Interview scale. Brazilian J Matern Child Health 2009; 9: 31-37.

7 Blanes L, Carmagnani MIS, Ferreira LM. Health-related quality of life of primary caregivers of persons with paraplegia. Spinal Cord 2007; 45: 399-403.

8 Ehrlich F, Bowring G, Draper B, Poulos C, Salgado R. Caring for carers - a national problem. Med J Aust 1992; 156: 590-592.

9 Scarpelli AC, Paiva SM, Pordeus IA, Varni JW, Viegas CM, Allison PJ. The Pediatric Quality of Life Inventory (PedsQL) family impact module: reliability and validity of the Brazilian version. Health Qual Life Outcomes 2008; 6: 35 .

10 Lorenzo CM, Xikota JC, Wayhs MC, Nassar SM, Pires MMS. Evaluation of the quality of life of children with celiac disease and their parents: a case-control study. Qual Life Res 2011; 21: 77-85.

11 Crowe TK, VanLeit B, Berghmans KK. Mothers' perceptions of child care assistance: the impact of a child's disability. Am J Occup Ther 2000; 54: 52-58.

12 Mugno D, Ruta L, D'Arrigo VG, Mazzone L. Impairment of quality of life in parents of children and adolescents with pervasive developmental disorder. Health Qual Life Outcomes 2007; 5: 22.

13 Panganiban-Corales AT, Medina MF. Family resources study: part 1: family resources, family function and caregiver strain. Childhood Cancer Asia Pac Fam Med 2011; 10: 14.

14 Lo M, Liu YH. Quality of life among older grandparent caregivers: a pilot study. J Adv Nurs 2006; 65: 1475-1485.

15 Covinsky KE, Newcomer R, Fox P, Wood J, Sands L, Dane K et al. Patients and caregiver characteristics associated with depression in caregivers of patients with dementia. J Gen Intern Med 2003; 18: 1006-1014.

16 Rösler-Schidlack B, Stummer H, Ostermann H. Health-related quality of life of family caregivers-evidence from Hesse. J Public Health 2011; 19: 269-280.

17 Belasco A, Barbosa D, Bettencourt AR, Diccini S, Sesso R. Quality of life of family caregivers of elderly patients on hemodialysis and peritoneal dialysis. Am J Kidney Dis 2006; 48: 955-963.

18 Takahashi M, Tanaka K, Miyaoka H. Depression and associated factors of informa caregivers versus professional caregivers of demented patients. Psychiatry Clin Neurosci 2005; 59: 473-480.

19 Takai M, Takahashi M, Iwamitsu Y, Ando N, Okazaki S, Nakajima K et al. The experience of burnout among home caregivers of patients with dementia: relations to depression and quality of life. Arch Gerontol Geriatr 2009; 49: e1-e5.

20 Pinquard $M$, Sorensen S. Differences between caregivers and noncaregivers in psychological health and physical health: a meta-analysis. Psychol Aging 2003; 18 : 250-267. 